\title{
Crystal growth and scintillation properties of multi-component oxide single crystals: Ce:GGAG and Ce:La-GPS
}

\author{
A. Yoshikawa ${ }^{1,2,3 *}$, K. Kamada ${ }^{2,3}$, S. Kurosawa ${ }^{1,2}$, Y. Shoji ${ }^{1,3}$, Y. Yokota $^{2}$, V. I. Chani ${ }^{1}$, M. \\ $\mathrm{Nikl}^{4}$ \\ ${ }^{1}$ Institute for Materials Research (IMR), Tohoku University, Sendai 980-8577, Japan \\ ${ }^{2}$ New Industry Creation Hatchery Center (NICHe), Tohoku University, Sendai 980-8579, \\ Japan \\ ${ }^{3}$ C\&A Corporation, 6-6-40 Aramaki Aza Aoba, Aoba-ku, Sendai 980-8579, Japan \\ ${ }^{4}$ Institute of Physics, AS CR, Cukrovarnická 10, 16253 Prague, Czech Republic \\ *Corresponding author: yoshikawa@imr.tohoku.ac.jp
}

\begin{abstract}
Crystal growth by micro-pulling-down, Czochralski, and floating zone methods and scintillation properties of $\mathrm{Ce}: \mathrm{Gd}_{3}(\mathrm{Ga}, \mathrm{Al})_{5} \mathrm{O}_{12}$ (Ce:GGAG) multi-component oxide garnets, and $\mathrm{Ce}: \mathrm{Gd}_{2} \mathrm{Si}_{2} \mathrm{O}_{7}$ (Ce:GPS) or Ce:(La,Gd) ${ }_{2} \mathrm{Si}_{2} \mathrm{O}_{7}$ (Ce:La-GPS) pyro-silicates are reviewed. GGAG crystals demonstrated practically linear dependences of some of the parameters including lattice constant, emission wavelength, and band gap on Ga content. However, emission intensity, light yield and energy resolution showed maxima for intermediate compositions. GGAG crystals had highest light yield of 56,000photon/MeV for Ga content of 2.7 atoms per garnet formula unit. Similarly the light yield and energy resolution of La-GPS showed the highest values of 40,000 photon/MeV and 4.4\%@662keV, respectively, for LaGPS containing $10 \%$ of La. Moreover, La-GPS demonstrated stable scintillation performance up to $200^{\circ} \mathrm{C}$.
\end{abstract}




\section{Introduction.}

Scintillating materials play important role in progress of a number of technical applications that include medical imaging, natural resource examination, inspection of radioactive elements producing radon gas in geology, security control, non-destructive analysis, neutron based inspection, high energy physics, laser and optical materials characterization. Therefore, demand for such substances including those existing in single crystal form has been always increasing.

The application of the scintillators in sensors of ionizing radiation is based on luminescence phenomenon. At first, the energy of incoming high energy photons/particles is absorbed by the scintillator. After that, the material is relaxing back to the ground state via reemission of part of this energy in the form of light. The coupled photodetector converts the generated light into an electrical signal that is convenient for further analysis of the nature and energy of incoming photons/particles. The light sensors used are photomultiplier tubes (PMT), photo-diodes, or silicon photo-multipliers.

The history of scintillators started just after discovery of the X-rays at the end of 19-th century [1]. Those materials coupled with photographic film were in a powder form. Later on, in the middle of the 20-th century, application of single crystal scintillators was also established.

Regarding gamma-ray scintillators, trends for the most important parameters are: high light output $\mathrm{Y}$ (photons/MeV), high scintillation speed $\tau_{\mathrm{s}}(\mathrm{ns})$, small energy resolution $\mathrm{R}_{\mathrm{FWHM}}$ (\%), low afterglow and low intrinsic activity, high effective atomic number Zeff, high density $\rho\left(\mathrm{g} / \mathrm{cm}^{3}\right)$, large size of the crystal $\left(10-100 \mathrm{~cm}^{3}\right)$, and low cost per crystal volume. Most of these parameters were reasonably optimized in $\operatorname{Pr}: \mathrm{Lu}_{3} \mathrm{Al}_{5} \mathrm{O}_{12}$ (Pr:LuAG) crystals developed for their application in radiation detectors, such as Positron Emission Mammography (PEM) [2]. After optimization of the growth conditions, high-quality Pr:LuAG crystals of about 4 inch in diameter were successfully produced by Czochralski technique. However, Pr:LuAG single crystals have considerable amount of anti-site defects that are formed as a result of partial substitution of $\mathrm{Al}^{3+}$ cations sited in octahedral positions of the garnet structure with $\mathrm{Lu}^{3+}$ that should mostly occupy dodecahedral sites of the garnet. Such kind of defects is associated with isoelectric trap. Supposedly, these anti-site defects are origin of the slow components in scintillation decay of Pr:LuAG [3].

As an alternative material, $\operatorname{Pr}: \mathrm{Lu}_{3}(\mathrm{Ga}, \mathrm{Al})_{5} \mathrm{O}_{12}$ crystals derived from $\operatorname{Pr}: \mathrm{LuAG}$ by partial isovalent substitution of $\mathrm{Al}^{3+}$ cations with $\mathrm{Ga}^{3+}$ were also considered. According to radio-luminescence spectra of $\operatorname{Pr}: \mathrm{Lu}_{3}(\mathrm{Ga}, \mathrm{Al})_{5} \mathrm{O}_{12}$ recorded at room temperature, 5d-4f 
luminescence was observed in all range of substitutions except $100 \%$ Ga (only $4 \mathrm{f}-4 \mathrm{f}$ luminescence of $\operatorname{Pr}^{3+}$ was detected). Moreover, it was found that defect related host luminescence disappeared at low content of $\mathrm{Ga}^{3+}(5 \%)$, but the light yield did not exceed that of Ga-free material.

Furthermore, light yield of the Ce-doped $\mathrm{Lu}_{3}(\mathrm{Ga}, \mathrm{Al})_{5} \mathrm{O}_{12}$ crystals containing 0,10 , and $20 \%$ of Ga was examined. According to previous report [4], the light yield of these crystals slightly depends on the growth atmosphere. Nevertheless, the crystals grown in oxidizing atmosphere had relatively low light yield. Increase of light yield was observed when $\mathrm{Al}^{3+}$ cations in $\mathrm{Ce}$ : $\mathrm{Lu}_{3} \mathrm{Al}_{5} \mathrm{O}_{12}$ were partially substituted with $\mathrm{Ga}^{3+}$. We note that light yield did not correlate with radio-luminescence intensity as the increase of the light yield was associated with suppression of slower components in the scintillation decay.

Recently, a number of multicomponent garnet-type materials including single crystals of $\mathrm{Ce}_{\mathrm{Lu}}(\mathrm{Ga}, \mathrm{Al})_{5} \mathrm{O}_{12}$ and $\mathrm{Ce}:(\mathrm{Gd}, \mathrm{RE})_{3}(\mathrm{Ga}, \mathrm{Al})_{5} \mathrm{O}_{12}$ [5-8] and transparent ceramic of $\mathrm{Ce}:(\mathrm{Gd}, \mathrm{Y})_{3} \mathrm{Al}_{5} \mathrm{O}_{12}$, Ce: $(\mathrm{Gd}, \mathrm{Y})_{3}(\mathrm{Sc}, \mathrm{Al})_{5} \mathrm{O}_{12}$, and $\mathrm{Ce}:(\mathrm{Gd}, \mathrm{Y})_{3}(\mathrm{Ga}, \mathrm{Al})_{5} \mathrm{O}_{12}$ [9-11] were also developed considering their application as scintillating materials.

The purpose of this report is to discuss the crystal growth and selected scintillation characteristics of two oxide single crystal families, namely Ce: $\mathrm{Gd}_{3}(\mathrm{Ga}, \mathrm{Al})_{5} \mathrm{O}_{12}$ (Ce:GGAG) garnets and $\mathrm{Ce}: \mathrm{Gd}_{2} \mathrm{Si}_{2} \mathrm{O}_{7}$ (Ce:GPS) or Ce:( $\left.\mathrm{La}, \mathrm{Gd}\right)_{2} \mathrm{Si}_{2} \mathrm{O}_{7}$ (Ce:La-GPS) pyro-silicates.

\section{Crystal Growth.}

Three methods of crystal growth were applied here for the inspection and optimization of the growth procedure and properties of the materials of interest. The preliminary testing of the growth process and the crystal behavior was performed using micro-pulling-down ( $\mu$-PD) process. This method is suitable laboratory tool that allows fabrication of single crystal specimens of several $\mathrm{mm}$ in dimensions within 5-10 hours. Normally 1-3 grams of starting material is sufficient to produce the melt necessary for the crystal growth. Such samples are acceptable for first characterization of their physical performance. These growths are also suitable for understanding the basic behavior of the melt including its viscosity and wetting properties with respect to the crucible material, evaporation of ingredients, segregation phenomena, etc.

When the growth of micro-scale crystals by the $\mu$-PD process is established, the crystal production by commercially more effective Czochralski (CZ) procedure is initiated. The $\mathrm{CZ}$ process requires considerable amount of starting materials of hundreds of grams up to kilogram's scale. Therefore, optimization of the melt composition and some of the growth 
parameters is preferable at the stage of $\mu$-PD growth. This allows to decrease consumption of time and make the material R\&D more cost-effective. Principles and schematic diagrams of both these methods are described in recent reviews [12-14]. The position of the floating zone method regarding the material and time consumption, and quality of the crystal produced, is most probably intermediate with respect to the above two methods.

\section{3. $\mathrm{Ce}: \mathrm{Gd}_{3}(\mathrm{Ga}, \mathrm{Al})_{5} \mathrm{O}_{12}$ and $\mathrm{Ce}:(\mathrm{Gd}, \mathrm{Lu})_{3}(\mathrm{Ga}, \mathrm{Al})_{5} \mathrm{O}_{12}$ Garnets.}

The growth of multi-component mixed crystals is generally difficult due to increased chemical complexity of the melt and especially segregation phenomenon that is observed in most complex oxides containing two or more types of cations. $\mathrm{Gd}_{3}(\mathrm{Ga}, \mathrm{Al})_{5} \mathrm{O}_{12}$ is not an exception. Non-substituted $\mathrm{Gd}_{3} \mathrm{Al}_{5} \mathrm{O}_{12}$ does not melt congruently as it is illustrated in Fig.1. As a result, $\mathrm{Gd}_{3} \mathrm{Al}_{5} \mathrm{O}_{12}$ single crystalline material cannot be produced from the melt of the same composition. One of the ways to resolve this problem is to find applicable flux and perform the growth by Top Seeded Solution Growth (TSSG). Another approach is to keep amount of all the key elements of the crystal as high as possible and to substitute only part of them to improve the phase diagram. In the best case scenario, such substitution may result in congruent-like behavior of the system. As a final result, CZ growth of such crystals directly from the melt becomes possible. Regarding $\mathrm{Gd}_{3}(\mathrm{Ga}, \mathrm{Al})_{5} \mathrm{O}_{12}$ crystals, congruent melting was expected in the vicinity of $\mathrm{Gd}_{3} \mathrm{Ga}_{3} \mathrm{Al}_{2} \mathrm{O}_{12}$ composition [16].

\subsection{Composition Selection. Micro-Pulling-Down ( $\mu$-PD) Crystal Growth.}

Firstly, tens of garnet crystals of different compositions were produced by the $\mu$-PD technique (Fig.2) to inspect suitability of the melt performance, the growth conditions, and scintillating properties of resulting materials. Prepared crystals contained different combinations of rare-earths in different portions. Also, various ratios between $\mathrm{Ga}^{3+}$ and $\mathrm{Al}^{3+}$ occupying octahedral and tetrahedral positions of the garnet structure were of interest. Moreover, number of isovalent and aliovalent substitutions in octahedral sites were attempted with $\mathrm{Lu}^{3+}, \mathrm{Y}^{3+}, \mathrm{Sc}^{3+}$. Finally, it was found that substitution with $\mathrm{Ga}^{3+}$ demonstrated the best overall performance.

Lattice constants of number of $(\mathrm{Gd}, \mathrm{Lu})_{3}(\mathrm{Ga}, \mathrm{Al})_{5} \mathrm{O}_{12}$ mixed crystals were measured using conventional X-ray diffraction (XRD) analysis to understand distribution of $\mathrm{Ga}^{3+}$ between different crystallographic sites of the garnet. The results are illustrated in Fig.3. In all the cases, the lattice constants increased linearly when content of $\mathrm{Gd}^{3+}$ and $\mathrm{Ga}^{3+}$ increased. 
All the tendencies demonstrated linear behavior in good agreement with the Vegard's law. This indicated random occupancy of $\mathrm{Ga}^{3+}$ in tetrahedral and octahedral sites.

\subsection{Scintillation characteristics}

The as produced $\mu$-PD crystals were studied regarding their scintillating performance. The results of evaluation of the radio-luminescence spectra of the $\mathrm{Ce}:(\mathrm{Gd}, \mathrm{Lu})_{3}(\mathrm{Ga}, \mathrm{Al})_{5} \mathrm{O}_{12}$ crystals of various chemical composition are presented in Fig.4.The measurements were performed at room temperature under X-ray excitation $(\mathrm{CuK} \alpha)$. The results demonstrated that in the case of relatively low Gd concentration (about 1 atom per garnet formula unit) the $\mathrm{Gd}^{3+} 4 \mathrm{f}-4 \mathrm{f}$ emission at $310 \mathrm{~nm}$ is very intense. However, in the garnets containing sufficiently high amount of the $\mathrm{Ce}^{3+}$ dopant this emission $(310 \mathrm{~nm})$ was not detected at all.

It is important to note that all the $\mathrm{Ce}:(\mathrm{Gd}, \mathrm{Lu})_{3} \mathrm{Ga}_{2} \mathrm{Al}_{3} \mathrm{O}_{12}$ crystals also demonstrated dominant emission in the range of 490-540 $\mathrm{nm}$ due to $5 \mathrm{~d}-4 \mathrm{f}$ transition of $\mathrm{Ce}^{3+}$. The position of this emission peak shifted to longer wavelengths for the garnets congaing greater amount of $\mathrm{Gd}^{3+}$. On the contrary, increasing $\mathrm{Ga}^{3+}$ content resulted in short-wavelength shift of the position of the peak maximum. These tendencies were consistent with similar studies accomplished in powder samples of this kind $[17,18]$.

Furthermore, analysis of the dependence of radio-luminescence $5 \mathrm{~d}^{1}-4 \mathrm{f}$ peak intensity on the crystal composition demonstrated that the intensity had maximum value for the crystals of $\mathrm{Ce}: \mathrm{Gd}_{3} \mathrm{Lu}_{0} \mathrm{Ga}_{2} \mathrm{Al}_{3} \mathrm{O}_{12}$ and $\mathrm{Ce}: \mathrm{Gd}_{2} \mathrm{Lu}_{1} \mathrm{Ga}_{3} \mathrm{Al}_{2} \mathrm{O}_{12}$ composition. Combining the two above compositions, the region of most efficient host material for scintillation applications has been determined to be in the range of $\operatorname{Gd}_{(2-3)} \mathrm{Lu}_{(0-1)} \mathrm{Ga}_{(2-3)} \mathrm{Al}_{(2-3)} \mathrm{O}_{12}$.

Energy spectrum of 1\% Ce-doped GGAG measured at room temperature using the

${ }^{137} \mathrm{Cs}$ source and avalanche photodiode (APD) registration is also presented in Fig.4. The results demonstrated that best light yield value of approximately 56,000photon/MeV was observed in the GGAG crystals containing $2.7 \sim 3.0$ atoms of $\mathrm{Ga}$ per garnet formula unit $[19,20]$. The best energy resolution was 5.3\%@662keV in the GGAG containing 2 atoms of Ga per formula unit.

By co-doping the GGAG crystals with $\mathrm{Mg}^{2+}$ or $\mathrm{Ca}^{2+}$, a part of $\mathrm{Ce}^{3+}$ cations in the GGAG is transformed to $\mathrm{Ce}^{4+}$ cations. The presence of $\mathrm{Ce}^{4+}$ centers makes the decay faster: $40 \mathrm{~ns}$ dominating decay time is observed in the fast scintillation decay component of $\mathrm{Mg}^{2+}$ codoped Ce:GGAG [21].

\subsection{Czochralski Growth}


Based on the optimization of the crystal composition discussed in Subsection 3.1 and 3.2, the $\mathrm{Gd}_{3} \mathrm{Ga}_{2.7} \mathrm{Al}_{2.3} \mathrm{O}_{12}$ host composition was selected for the first growth of bulk crystals by the Czochralski method. The growth was performed from iridium crucibles of $100 \mathrm{~mm}$ in diameter in $\mathrm{Ar}+1.5 \% \mathrm{O}_{2}$ atmosphere to protect the crucible material from oxidation. $\mathrm{Lu}_{3} \mathrm{Al}_{2} \mathrm{O}_{12}$ seed oriented along $<100>$ direction was used to initiate solidification of the target material. The crystal diameter was set to be about $50 \mathrm{~mm}$ (about 2 inches). The growths were performed at pulling rate of $0.8 \mathrm{~mm} / \mathrm{hr}$ and rotation rate of $6 \mathrm{rpm}$.

The results of the growths carried out from the melts containing different amount of Ce-dopant $(1 \%, 2.5 \%$, and $3 \%)$ are illustrated in Fig.5. The crystals were transparent and crack-free. This was in good agreement with the preliminary growth results obtained previously using the $\mu$-PD method (Fig.2).

As a second step, search for other appropriate crystal compositions that belong to the compositional range of $\mathrm{Gd}_{(2-3)} \mathrm{Lu}_{(0-1)} \mathrm{Ga}_{(2-3)} \mathrm{Al}_{(2-3)} \mathrm{O}_{12}$ approved in previous subsection was also performed. Thus, growth of the crystals with different $\mathrm{Ga} / \mathrm{Al}$ ratio was attempted. The growth conditions were similar to those for the above discussed $\mathrm{Gd}_{3} \mathrm{Ga}_{2.7} \mathrm{Al}_{2.3} \mathrm{O}_{12}$ host crystal. The results of the growth of this crystal set corresponding to $\mathrm{Gd}_{3} \mathrm{Ga}_{2 .} \mathrm{Al}_{2.3} \mathrm{O}_{12}$, $\mathrm{Gd}_{3} \mathrm{Ga}_{2.4} \mathrm{Al}_{2.6} \mathrm{O}_{12}$, and $\mathrm{Gd}_{3} \mathrm{Ga}_{2} \mathrm{Al}_{3} \mathrm{O}_{12}$ hosts are summarized in Fig.6. The quality of the crystals was not as good as those produced with fixed $\mathrm{Ga} / \mathrm{Al}$ ratio of $2.7: 2.3$ $\left(\mathrm{Gd}_{3} \mathrm{Ga}_{2.7} \mathrm{Al}_{2.3} \mathrm{O}_{12}\right)$. Only the latter crystal was a single phase material. The crystal produced from the $\mathrm{Gd}_{3} \mathrm{Ga}_{2.4} \mathrm{Al}_{2.6} \mathrm{O}_{12}$ melt contained perovskite phase at the beginning of the growth while that produced from the $\mathrm{Gd}_{3} \mathrm{Ga}_{2} \mathrm{Al}_{3} \mathrm{O}_{12}$ melt contained garnet phase at the end part only.

Thus, the best growth results for the $\mathrm{Gd}_{3}(\mathrm{Ga}, \mathrm{Al})_{5} \mathrm{O}_{12}$ garnet subfamily corresponded to the crystals containing from 2.7 to 3.0 atoms of Ga per formula unit. The materials of this composition range also had the best light yield around 56,000photon/MeV (Fig.4). It is noted that best energy resolution of $5.3 \%$ for $662 \mathrm{keV}$ was observed for the $\mathrm{Gd}_{3} \mathrm{Ga}_{2} \mathrm{Al}_{3} \mathrm{O}_{12}$ crystal composition. It is assumed that this scintillator can be considered as a material of choice because it is non-hygroscopic; it well couples to Si-based photo detectors sensitivity curve, and its chemical stability and mechanical hardness are sufficient for production of very thin pixels necessary for high-resolution imaging systems.

Czochralski grown $\mathrm{Mg}^{2+}$ co-doped Ce:GGAG was also examined. As it was mentioned above, the formation of $\mathrm{Ce}^{4+}$ centers makes the scintillation decay faster. The decay time within 20 - 50ns is observed in the dominating fast scintillation decay component of $\mathrm{Mg}^{2+}$ co-doped Ce: GGAG [22]. The timing resolution of this crystal becomes as short as 200ps. Taking into consideration the reported timing resolution of Ce:LYSO ( 200ps) [23] 
and its light yield around 32000 phot/MeV, the Ce,Mg:GGAG can certainly be an attractive candidate for Positron Emission Tomography (PET) application.

\section{Rare-Earth Pyrosilicates}

Rare-earth pyrosilicates (disilicates) belong to another family of perspective scintillating crystals [24-28]. Gadolinium pyro-silicate, $\mathrm{Ce}: \mathrm{Gd}_{2} \mathrm{Si}_{2} \mathrm{O}_{7}$ (Ce:GPS) is one of the members of this family. It melts incongruently. In spite of that, it can be grown from the melt when heavy Ce-doping is performed (approximately 10 at.\% regarding $\mathrm{Gd}^{3+}$ host cations to be substituted). This doping modifies the phase diagram and stabilizes the crystal growth process [26, 27]. However, such a high Ce-concentration leads to reduced light output because of self-absorption and concentration quenching. On the other hand, optimal $\mathrm{Ce}^{3+}$ content with respect to the sum of host rare-earth cations is approximately 1 at. $\%$ according to [28]. However, $1 \%$ amount of $\mathrm{Ce}^{3+}$ is not sufficient to improve stability of the GPS formation. Thus, optimization of the composition in the $(\mathrm{Ce}, \mathrm{Gd})_{2} \mathrm{Si}_{2} \mathrm{O}_{7}$ system is almost impossible.

It is also known that some of the other disilicate crystals formed by small rare-earth metals including $\mathrm{Lu}_{2} \mathrm{Si}_{2} \mathrm{O}_{7}, \mathrm{Yb}_{2} \mathrm{Si}_{2} \mathrm{O}_{7}$, and $\mathrm{Er}_{2} \mathrm{Si}_{2} \mathrm{O}_{7}$ melt congruently [28]. As for the $\mathrm{Gd}_{2} \mathrm{Si}_{2} \mathrm{O}_{7}$, it melts incongruently at $1720^{\circ} \mathrm{C}$ with decomposition to $\mathrm{Gd}_{4}\left(\mathrm{SiO}_{4}\right)_{3}$ orthosilicate and liquid phase. Thus, simple solidification of $\mathrm{Gd}_{2} \mathrm{Si}_{2} \mathrm{O}_{7}$ stoichiometric melt results in formation of non-desired $\mathrm{Gd}_{4}\left(\mathrm{SiO}_{4}\right)_{3}$ phase.

\subsection{Crystal Growth by Floating Zone.}

Recent report [28] demonstrated that partial substitution of $\mathrm{Gd}^{3+}$ with another large rare-earth cation of $\mathrm{La}^{3+}$ (for about 10 at\%) also stabilizes the formation of $\mathrm{Gd}_{2} \mathrm{Si}_{2} \mathrm{O}_{7}$ pyrosilicate phase. Thus, regarding phase formation, $\mathrm{La}^{3+}$ an $\mathrm{Ce}^{3+}$ have similar effect. Such a matrix of mixed $(\mathrm{La}, \mathrm{Gd})_{2} \mathrm{Si}_{2} \mathrm{O}_{7}$ (La-GPS) pyrosilicate host crystal can be also doped with the active $\mathrm{Ce}^{3+}$-dopant, and the $\mathrm{Ce}$ content in the $(\mathrm{La}, \mathrm{Gd})_{2} \mathrm{Si}_{2} \mathrm{O}_{7}$ crystal can be as low as necessary. If Ce content is low enough, then concentration quenching is not observed. The growth of Ce-doped La-GPS crystals by floating zone (FZ) method [29-31] was performed under following conditions: The composition of the source polycrystalline rod was $\mathrm{La}_{0.18} \mathrm{Ce}_{0.02} \mathrm{Gd}_{1.8} \mathrm{Si}_{2} \mathrm{O}_{7}$. After consolidation of the starting powder in the rod shape, it was sintered at temperature of $1300^{\circ} \mathrm{C}$ for 10 hours in air atmosphere. The growth was performed via melting the rod and its re-solidification to single crystalline bulk in Ar atmosphere (gas flow of $0.51 / \mathrm{min}$ ). The pulling rate applied was in the range of $2-5 \mathrm{~mm} / \mathrm{h}$, and rotation of the crystal was $20 \mathrm{rpm}$. The as grown crystals and typical 
specimen ready for characterization are illustrated in Fig.7.

\subsection{Crystal Growth by Czochralski Method.}

Optimal $\mathrm{La} / \mathrm{Gd}$ ratio for the $(\mathrm{La}, \mathrm{Gd})_{2} \mathrm{Si}_{2} \mathrm{O}_{7}$ crystals regarding their melting and/or solidification behavior is not known. Therefore, first growth of the Ce-doped ( $\mathrm{La}, \mathrm{Gd})_{2} \mathrm{Si}_{2} \mathrm{O}_{7}$ crystals was performed from the melt containing approximately equal amounts of $\mathrm{La}_{2} \mathrm{O}_{3}$ and $\mathrm{Gd}_{2} \mathrm{O}_{3}$. The growth was carried out from iridium crucible using $\mathrm{CZ}$ system with inductive heating in $\mathrm{Ar}+\mathrm{O}_{2}(2 \%)$ atmosphere [32]. Composition of the starting material was $\mathrm{La}_{0.98} \mathrm{Ce}_{0.02} \mathrm{Gd}_{1.0} \mathrm{Si}_{2} \mathrm{O}_{7}$. The conditions of the process were as follows: pulling rate was $0.5 \mathrm{~mm} / \mathrm{h}$, seed orientation was $<100>$, and rotation rate was $12 \mathrm{rpm}$. The as grown crystal was $25 \mathrm{~mm}$ in diameter and about 50 $\mathrm{mm}$ in length regarding its cylindrical part having constant diameter (Fig.8). It had some cracks and macro-defects demonstrating that following optimization of the melt composition and/or the growth conditions are necessary. Nevertheless, some fragments of the material had reasonable optical quality. Therefore, two specimens $5 \times 5 \times 1 \mathrm{~mm}^{3}$ (samples A and B) were cut from the crystal from the sections corresponding to different solidification fractions. The specimens were polished for following characterization as it is also illustrated in Fig.8.

Surprisingly, the crystal (Fig.8) was very uniform along its growth axis considering its chemical composition as it is demonstrated in Fig.9. No significant difference was detected between the samples A and B. The host cations and Ce-dopant were distributed almost uniformly illustrating that segregation of the cations between the melt and the solid phase of the crystal is not critical phenomenon affecting the growth process and quality of the crystals.

\subsection{Optical properties and radiation response}

Because of chemical similarity of the samples A and B cut from the crystal fractions corresponding to different stages of the growth, similarity of their physical performance was also expected. Experimental examinations of these specimens confirmed exceptional match of their spectroscopic properties (Fig.10). Transmittance spectra (Fig.10, top) were measured using JASCO V-530 UV-VIS-NIR spectrophotometer in spectral range from 200 to $900 \mathrm{~nm}$. The spectra were almost identical except negligible deviations. The photo-luminescent spectra (Fig 10, middle) were measured using spectro-fluorometer FLS920 of Edinburgh Instruments with Xe lamp as an excitation source. Also, no difference between photo-luminescent properties of both specimens was observed. Finally, radio-luminescent spectra we examined using spectrofluorometer FLS920 of Edinburgh Instrument and 5.5 MeV alpha rays from Am-241 as an excitation source (Fig.10, below), and again the results were very similar. 
Fig.11 illustrates pulse height spectra of $(\mathrm{La}, \mathrm{Gd})_{2} \mathrm{Si}_{2} \mathrm{O}_{7}$ crystal recorded under ${ }^{137} \mathrm{Cs}$ irradiation. The signals were registered with photomultiplier tube (PMT) R7600-200 (Hamamatsu). Highest performance characterized by light yield of 40,000 photon/MeV was observed in the $(\mathrm{La}, \mathrm{Gd})_{2} \mathrm{Si}_{2} \mathrm{O}_{7}$ crystals containing $10 \%$ of $\mathrm{La}$. We note that $\mathrm{Ce}^{3+}$ center in these crystals shows the onset of thermal quenching/ionization above $150^{\circ} \mathrm{C}$ [33].

\section{Summary}

Crystal growth of two novel scintillating material families of $\mathrm{Ce}: \mathrm{Gd}_{3}(\mathrm{Ga}, \mathrm{Al})_{5} \mathrm{O}_{12}$ (Ce:GGAG) garnets and $\mathrm{Ce}: \mathrm{Gd}_{2} \mathrm{Si}_{2} \mathrm{O}_{7}$ (Ce:GPS) or $\mathrm{Ce}(\mathrm{La}, \mathrm{Gd})_{2} \mathrm{Si}_{2} \mathrm{O}_{7}$ (Ce:La-GPS) pyro-silicates are reported to be promising substances for practical applications. In GAGG, almost all the parameters including lattice constant, emission wavelength, band gap and other ones change linearly with Ga content. Ce:GAGG single crystal demonstrated highest performance of 56,000 photon/ $\mathrm{MeV}$ at $\mathrm{Ga}$ content of 2.7 atoms per garnet formula unit. Light yield and energy resolution of La-GPS show the highest values of 40,000 photon/ $\mathrm{MeV}$ and $4.4 \% @ 662 \mathrm{keV}$ in the crystals containing 10\% of La. $\mathrm{Ce}^{3+}$ centers in the La-GPS crystals demonstrated stable high quantum efficiency, not negatively affected neither by thermal quenching nor excited state ionization, at temperatures up to $150^{\circ 0} \mathrm{C}$. This is especially important for the high temperature application such as well logging.

\section{Acknowledgements}

This work is partially supported by (i) Japan Society for the Promotion of Science (JSPS) Grant-in-Aid for Exploratory Research (AY), (ii) the funding program for next generation world-leading researchers, JSPS, (iii) Development of Systems and Technology for Advanced Measurement and Analysis, Japan Science and Technology Agency (JST), (iv) Adaptable \& Seamless Technology Transfer Program through Target-driven R\&D (A-STEP), JST. (v) Supporting Industry program, Ministry of Economy, Trade and Industry (METI). In addition, we would like to thank following persons for their support: Mr. Yoshihiro Nakamura in Institute of Multidisciplinary Research for Advanced Materials (IMRAM), Tohoku University and Mr. Hiroshi Uemura, Ms. Keiko Toguchi and Ms. Megumi Sasaki, Ms. Yuka Takeda, Ms. Kuniko Kawaguchi in IMR. Some part of this work was carried out under the collaboration program of Cooperative Research and Development Center for Advanced Materials (CRDAM), IMR, Tohoku. University. Authors thanks to Mr. Sugawara, Ms. Nomura in CRDAM. 


\section{References}

1. W. C. Rontgen, On a new kind of rays 1896 Science 3 (1896) 227-231

2. A. Yoshikawa, T. Yanagida, K. Kamada, Y. Yokota, J. Pejchal, A. Yamaji, Y. Usuki, S. Yamamoto, M. Miyake, K. Kumagai, K. Sasaki, T.R. dos Santos, M. Baba, M. Ito, M. Takeda, N. Ohuchi, M. Nikl, Positron emission mammography using Pr:LuAG scintillator - Fusion of optical material study and systems engineering, Opt. Mat. 32 (2010) 12941297.

3. M. Nikl, A. Yoshikawa, K. Kamada, K. Nejezchleb, C.R. Stanek, J.A. Mares, K. Blazek, Progress in Crystal Growth and Characterization of Materials 59 (2013) 47-72

4. D.J. Robbins, B. Cockayne, B. Lent, C. N. Duckworth, J. L. Glasper, Investigation of competitive recombination processes in rare-earth activated garnet phosphors, Physical Review B 19 (1979) 1254-1269.

5. H. Ogino, A. Yoshikawa, M. Nikl, J. A. Mares, J.-i. Shimoyama, K. Kishioa, Growth and optical properties of $\mathrm{Lu}_{3}(\mathrm{Ga}, \mathrm{Al})_{5} \mathrm{O}_{12}$ single crystals for scintillator application, J. Cryst. Growth 311 (2009) 908-911.

6. K. Kamada, T. Endo, K. Tsutumi, T. Yanagida, Y. Fujimoto, A. Fukabori, A. Yoshikawa, J. Pejchal, M. Nikl, Composition engineering in cerium-doped ( $\mathrm{Lu}, \mathrm{Gd})_{3}(\mathrm{Ga}, \mathrm{Al})_{5} \mathrm{O}_{12}$ single-crystal scintillators, Crystal Growth and Design 11 (2011) 4484-4490.

7. A. Yoshikawa, Y. Fujimoto, A. Yamaji, S. Kurosawa, J. Pejchal, M. Sugiyama, S. Wakahara, Y. Futami, Y. Yokota, K. Kamada, K. Yubuta, T. Shishido, M. Nikl, Opt. Mat. 35 (2013) 1882-1886

8. K. Kamada, T Yanagida, J Pejchal, M Nikl, T Endo, K Tsutumi, Y Fujimoto, A Fukabori and A. Yoshikawa, J. Phys. D: Appl. Phys. 44 (2011) 505104-505109

9. W. Zhao, C. Mancini, D. Amans, G. Boulon, T. Epicier, Y. Min, H. Yagi, T. Yanagitani, T. Yanagida, A. Yoshikawa, Evidence of the inhomogeneous Ce3+ distribution across grain boundaries in transparent polycrystalline $\mathrm{Ce}^{3+}$-Doped $(\mathrm{Gd}, \mathrm{Y})_{3} \mathrm{Al}_{5} \mathrm{O}_{12}$ garnet optical ceramics, Jpn. J. Appl. Phys. 49 (2010) 022602.

10. N. J. Cherepy, J. D. Kuntz, J. J. Roberts, T. A. Hurst, O. B. Drury, R. D. Sanner, T. M. Tillotson, S. A. Payne, Transparent Ceramic Scintillator Fabrication, Properties and Applications, in: LLNL-PROC-406543, SPIE- Hard X-Ray, Gamma-Ray, and Neutron Detector Physics X, San Diego, CA, United States, August 10, 2008 through August 14, 2008. 
11. N.J. Cherepy, S.A. Payne, B.W. Sturm, J.D. Kuntz, Z.M. Seeley, B.L. Rupert, R.D. Sanner, O.B. Drury, T.A. Hurst, S.E. Fisher, M. Groza, L. Matei, A. Burger, R. Hawrami, K.S. Shah, L.A. Boatner, Comparative Gamma Spectroscopy with SrI2(Eu), GYGAG(Ce) and Bi-loaded Plastic Scintillators, in: (2010) IEEE Nuclear Science Symposium Conference Record, art. no. 5873975, 1288-1291. ISBN: 978-142449106-3, doi: 10.1109/NSSMIC.2010.5873975

12. A. Yoshikawa, M. Nikl, G. Boulon, T. Fukuda, Opt. Mat. 30 (2007) 6-10

13. A. Yoshikawa, V. Chani, Growth of Optical Crystals by the Micro-Pulling-Down Method, MRS Bulletin 34 (2009) 266-270.

14. A. Yoshikawa, V. Chani, M. Nikl, Czochralski growth and properties of scintillating crystals, Acta Phys. Polonica A, 124, (2013) 250-264.

15. Y. H. Han, M. Nagata, N. Uekawa and K. Kakegawa, Eutectic $\mathrm{Al}_{2} \mathrm{O}_{3}-\mathrm{GdAlO}_{3}$ composite consolidated by combined rapid quenching and spark plasma sintering technique, British Ceramic Transactions 103 (2004) 219-222.

16. H. Kimura, H. Maeda, M. Sato, Czochralski growth of $\mathrm{Gd}_{3}\left(\mathrm{Ga}_{1-\mathrm{x}} \mathrm{Al}_{\mathrm{x}}\right)_{5} \mathrm{O}_{12}$ single crystals, J. Cryst. Growth 74 (1986) 187-190.

17. J. L. Wu, G. Gundiah, A. K. Cheetham, Chemical Physics Letters, 441 (2007) 250-254

18. M. Kottaisamy, P. Thiyagarajan, J. Mishra, J., et al, Mater. Res. Bullet, 43 (2008) 16571663.

19. K. Kamada, T Yanagida, J Pejchal, M Nikl, T Endo, K Tsutumi, Y Fujimoto, A Fukabori and A. Yoshikawa, J. Cry. Growth, 352 (2012)88-90

20. K. Kamada, S. Kurosawa, P. Prusa, M. Nikl, V. V. Kochurikhin, T. Endo, K. Tsutumi, H. Sato, Y. Yokota, K. Sugiyama, A. Yoshikawa, Opt. Mater. 36(2014)1942-1945

21. K. Kamada, M. Nikl, S. Kurosawa, A. Beitlerova, A. Nagura, Y. Shoji, J. Pejchal, Y. Ohashi, Y. Yokota, and A. Yoshikawa, Opt. Mater. DOI 10.1016/j.optmat.2014.10.008, (in press)

22. K. Kamada, A. Nagura, S.Yamamoto, M. Nikl, S. Kurosawa, Y. Shoji, J. Pejchal, Y. Ohashi, Y. Yokota, and A. Yoshikawa, going to submit to Adv. Mater.

23. W. Moses, Recent advances and future advances in time-of-flight PET. Nucl. Instr. Meth. Phys. Research A 580 (2007) 919-924

24. C. Yan, G. Zhao, Y. Hang, L. Zhang, J. Xu, Czochralski growth and crystal structure of cerium-doped $\mathrm{Lu}_{2} \mathrm{Si}_{2} \mathrm{O}_{7}$ scintillator, Mat. Lett. 60 (2006) 1960-1963. 
25. H. Feng, D. Ding, H. Li, S. Lu, S. Pan, X. Chen, G. Ren, Cerium concentration and temperature dependence of the luminescence of $\mathrm{Lu}_{2} \mathrm{Si}_{2} \mathrm{O}_{7}: \mathrm{Ce}$ scintillator, J. Alloys and Comp. 509 (2011) 3855-3858.

26. S. Kawamura, J. H. Kaneko, M. Higuchi, T. Yamaguchi, J. Haruna, Y. Yagi, K. Susa, F. Fujita, A. Homma, S. Nishiyama, K. Kurashige, H. Ishibashi, and M. Furusakaet, Floating Zone Growth and Scintillation Characteristics of Cerium-Doped Gadolinium Pyrosilicate Single Crystals, IEEE Trans. on Nucl. Sci., 54 (2007) 1383-1386.

27. O. Sidletskiy, V. Baumer, I. Gerasymov, B. Grinyov, K. Katrunov, N Starzhinsky, O. Tarasenko, V. Tarasov, S. Tkachenko, O. Voloshina, O. Zelenskaya, Gadolinium pyrosilicate single crystals for gamma ray and thermal neutron monitoring, Rad. Meas. 45 (2010) 365-368.

28. I. Gerasymov, O. Sidletskiy, S. Neicheva, B. Grinyov, V. Baumer, E. Galenin, K. Katrunov, S. Tkachenko, O.Voloshina, A.Zhukov, Growth of bulk gadolinium pyrosilicate single crystals for scintillators, J. Cryst. Growth 318 (2011) 805-808.

29. A. Suzuki, S. Kurosawa, T. Shishido, J. Pejchal, Y. Yokota, Y. Futami, A. Yoshikawa, Fast and High-Energy-Resolution Oxide Scintillator: Ce-Doped (La, Gd) ${ }_{2} \mathrm{Si}_{2} \mathrm{O}_{7}, \mathrm{Appl}$. Phys. Express 5 (2012) 102601(1-3).

30. S. Kurosawa, A. Suzuki, T. Shishido, J. Pejchal, Y. Yokota, A. Yoshikawa, Performance of Ce-Doped ( $\mathrm{La}, \mathrm{Gd})_{2} \mathrm{Si}_{2} \mathrm{O}_{7}$ Scintillator with an avalanche photodiode, Nucl. Instr. Meth A744 (2014) pp.30-34.

31. S. Kurosawa, T. Shishido, T. Sugawara, A. Nomura, K. Yubuta, A. Suzuki, R. Murakami, J. Pejchal, Y. Yokota, K. Kamada and A. Yoshikawa, Scintillation Properties of Ce:(La, Gd) ${ }_{2} \mathrm{Si}_{2} \mathrm{O}_{7}$ at High Temperature, Nucl. Instr. Meth A accepted.

32. A. Yoshikawa, S. Kurosawa, Y. Shoji, V. I. Chani, K. Kamada, Y. Yokota, Y. Ohashi, Cryst. Growth \& Design (2015) in press.

33. M. Nikl, S. Kurosawa, A. Yoshikawa, et al., submitted to J. Phys. Chem. C 


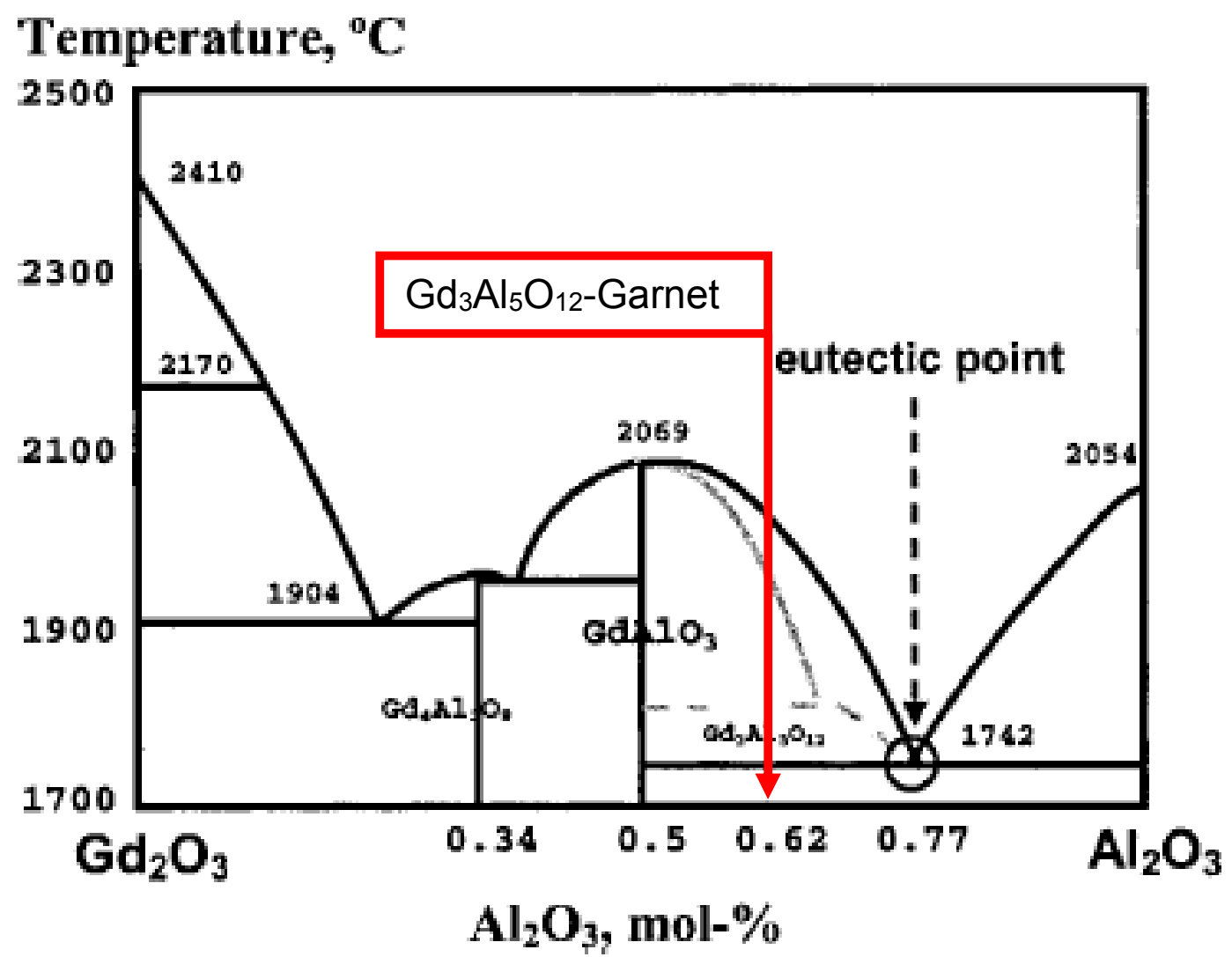

Fig.1. Phase diagram of binary $\mathrm{Gd}_{2} \mathrm{O}_{3}-\mathrm{Al}_{2} \mathrm{O}_{3}$ system [14] and composition corresponding to stoichiometric $\mathrm{Gd}_{3} \mathrm{Al}_{5} \mathrm{O}_{12}$-garnet. 


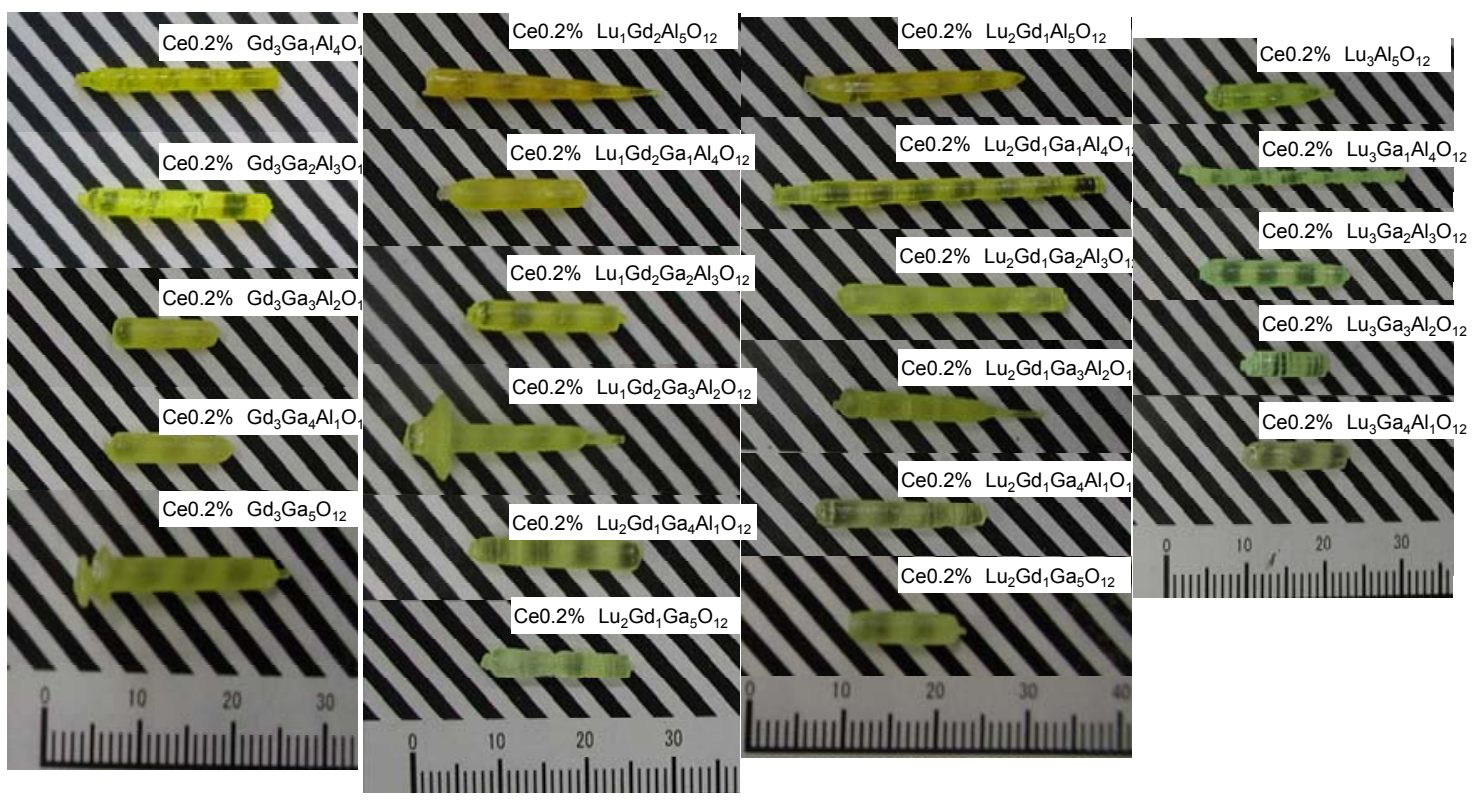

Fig.2. View of the $(\mathrm{Gd}, \mathrm{Lu})_{3}(\mathrm{Ga}, \mathrm{Al})_{5} \mathrm{O}_{12}$ mixed crystals produced by the micro-pulling-down technique. 


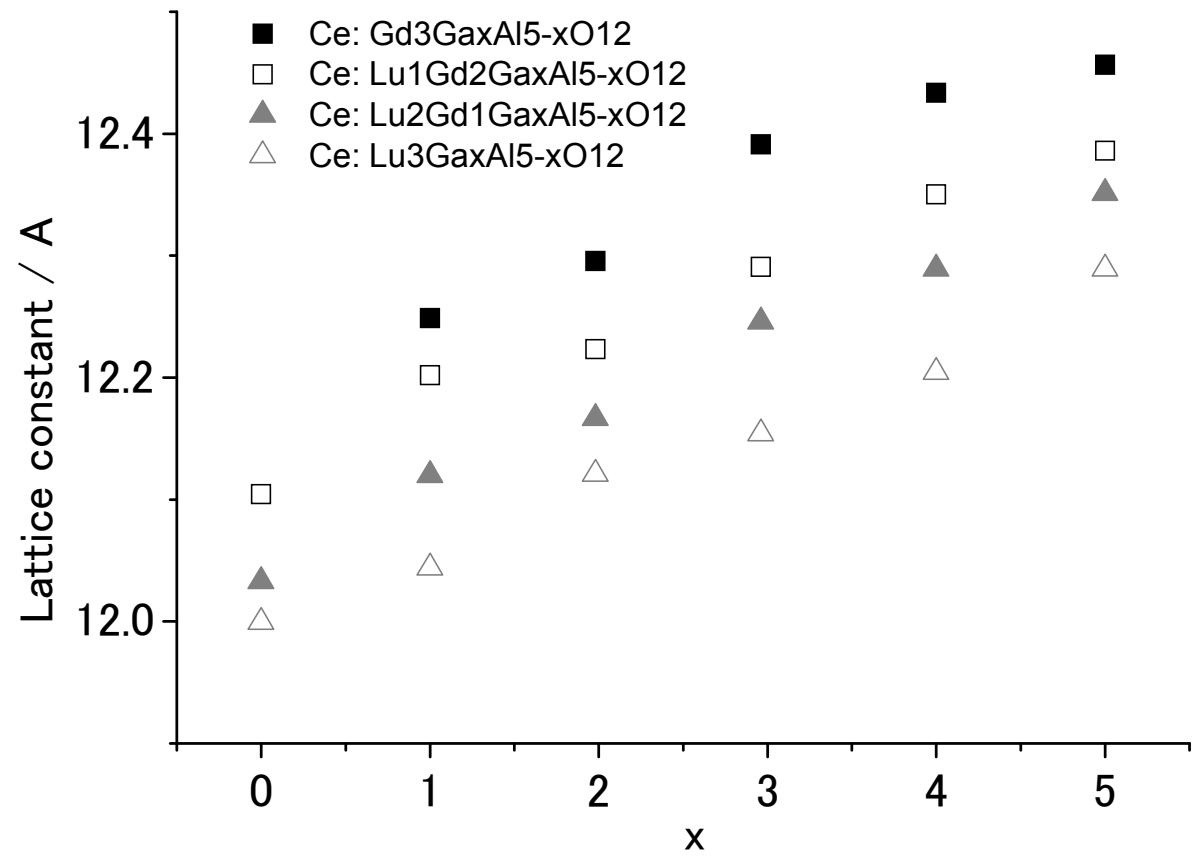

Fig.3. Lattice constants of the $(\mathrm{Gd}, \mathrm{Lu})_{3}(\mathrm{Ga}, \mathrm{Al})_{5} \mathrm{O}_{12}$ mixed crystals vs. Ga content. 

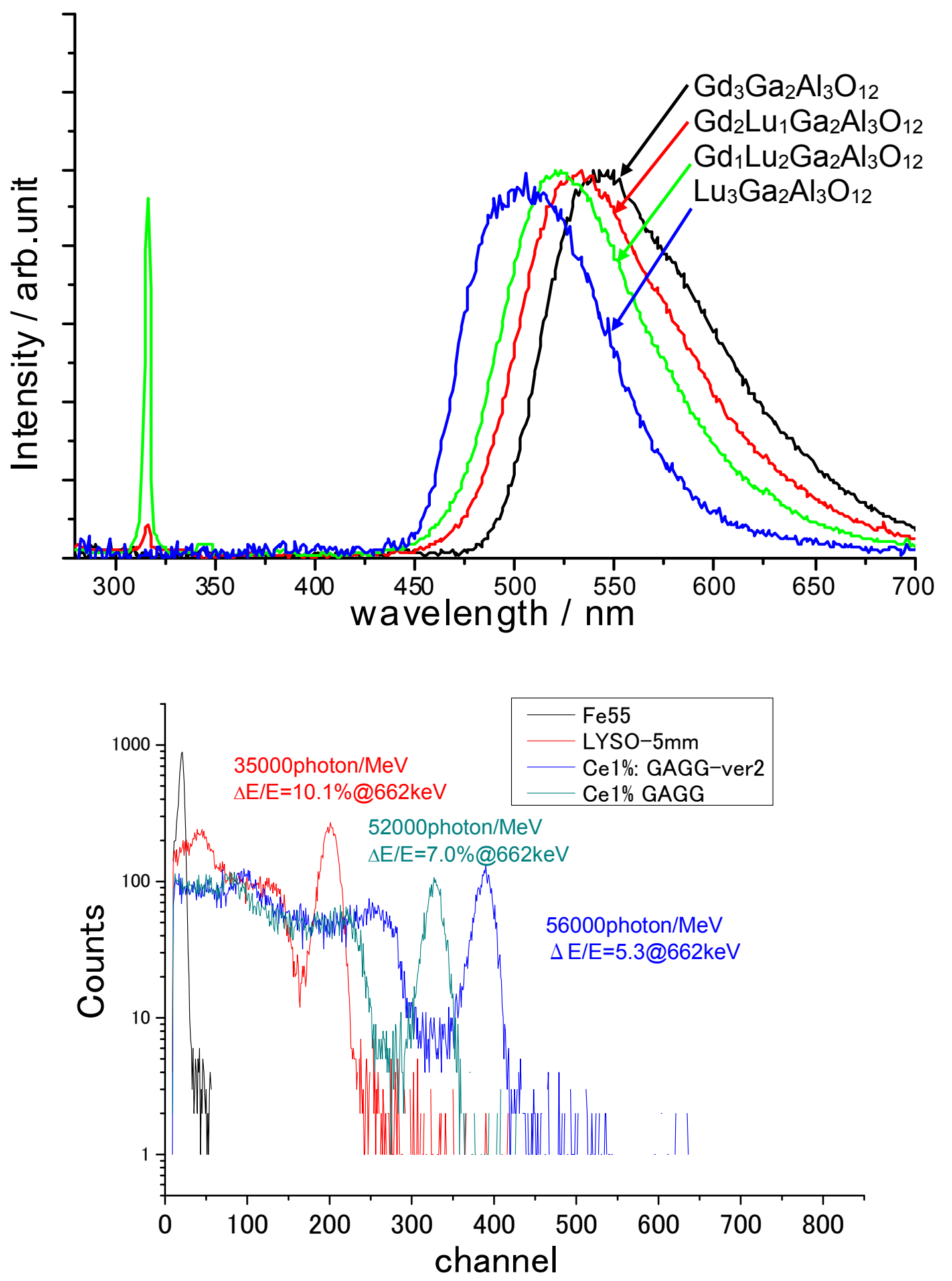

Fig.4. Radio-luminescence spectra of various $\mathrm{Ce}:(\mathrm{Gd}, \mathrm{Lu})_{3} \mathrm{Ga}_{2} \mathrm{Al}_{3} \mathrm{O}_{12}$ crystals with different Gd:Lu ratio (top) and energy spectrum of $1 \%$ Ce-doped GGAG measured at room temperature using the ${ }^{137} \mathrm{Cs}$ source and avalanche photodiode (APD) registration (bottom). 


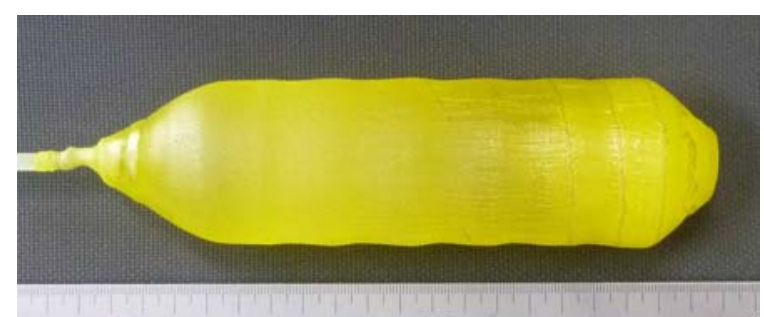

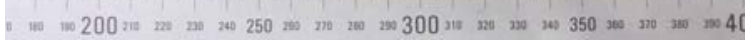
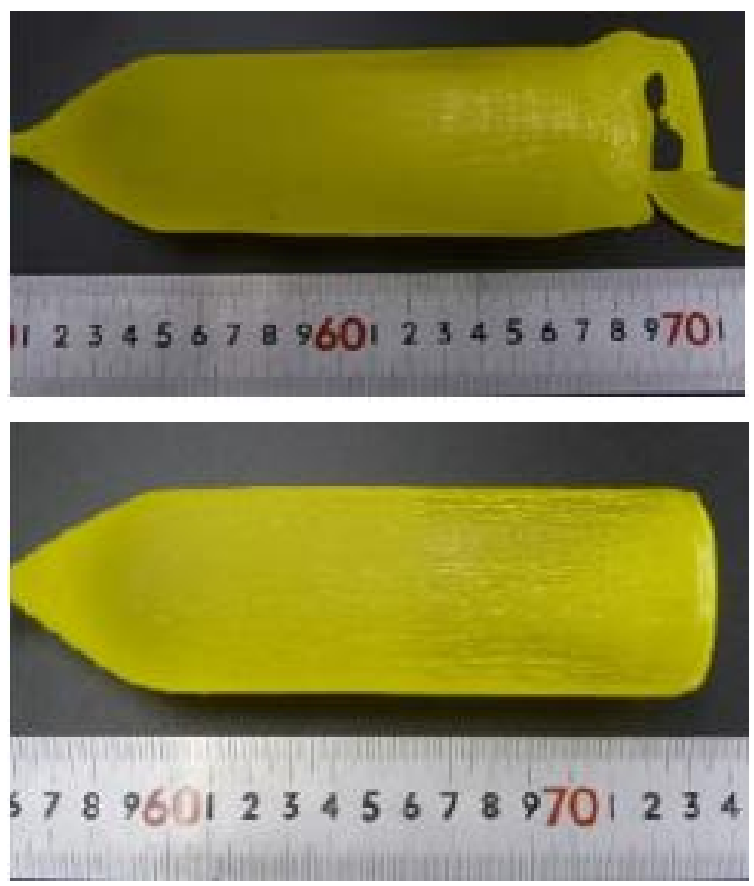

Fig.5 View of the $\mathrm{Ce}: \mathrm{Gd}_{3} \mathrm{Ga}_{2 .} \mathrm{Al}_{2.3} \mathrm{O}_{12}$ single crystals produced by Czochralski method. The Ce content was $1 \%, 2.5 \%$ and $3 \%$ (from top to bottom). Scales are in $\mathrm{mm}$. 


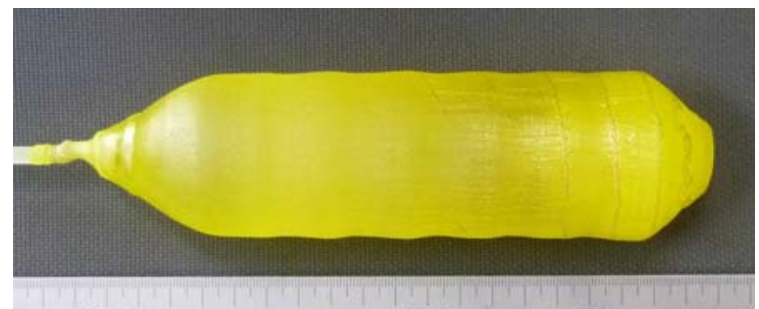

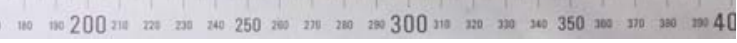
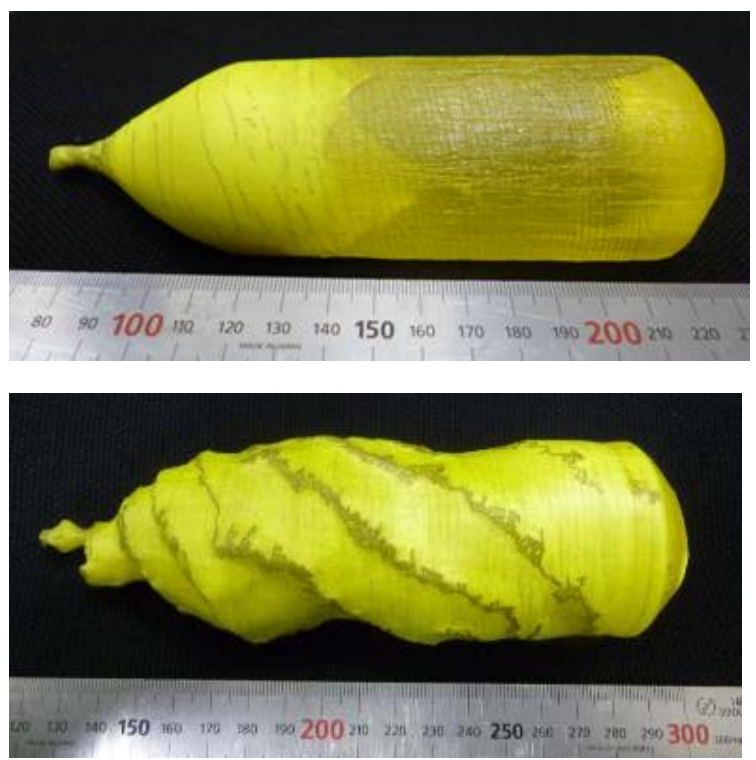

Fig.6. View of $1 \%$ Ce-doped $\mathrm{Gd}_{3} \mathrm{Ga}_{2.7} \mathrm{Al}_{2.3} \mathrm{O}_{12}, \mathrm{Gd}_{3} \mathrm{Ga}_{2.4} \mathrm{Al}_{2.6} \mathrm{O}_{12}$, and $\mathrm{Gd}_{3} \mathrm{Ga}_{2} \mathrm{Al}_{3} \mathrm{O}_{12}$ single crystals produced by Czochralski method (from top to bottom). Scales are in mm. 

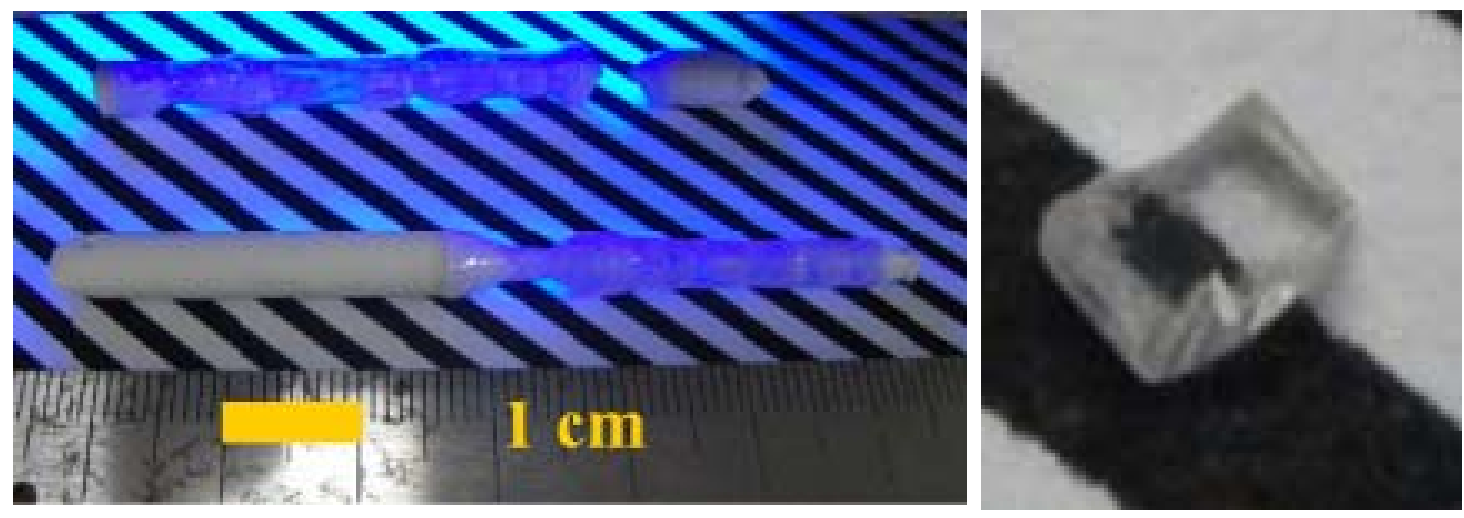

Fi.7 Appearance of the $\mathrm{La}_{0.02} \mathrm{Ce}_{0.18} \mathrm{Gd}_{1.8} \mathrm{Si}_{2} \mathrm{O}_{7}$ crystals as grown by the floating zone method (left) and view of the specimen of about $2 \times 2 \mathrm{~mm}$ in cross-section (right). Scale is in $\mathrm{mm}$. 


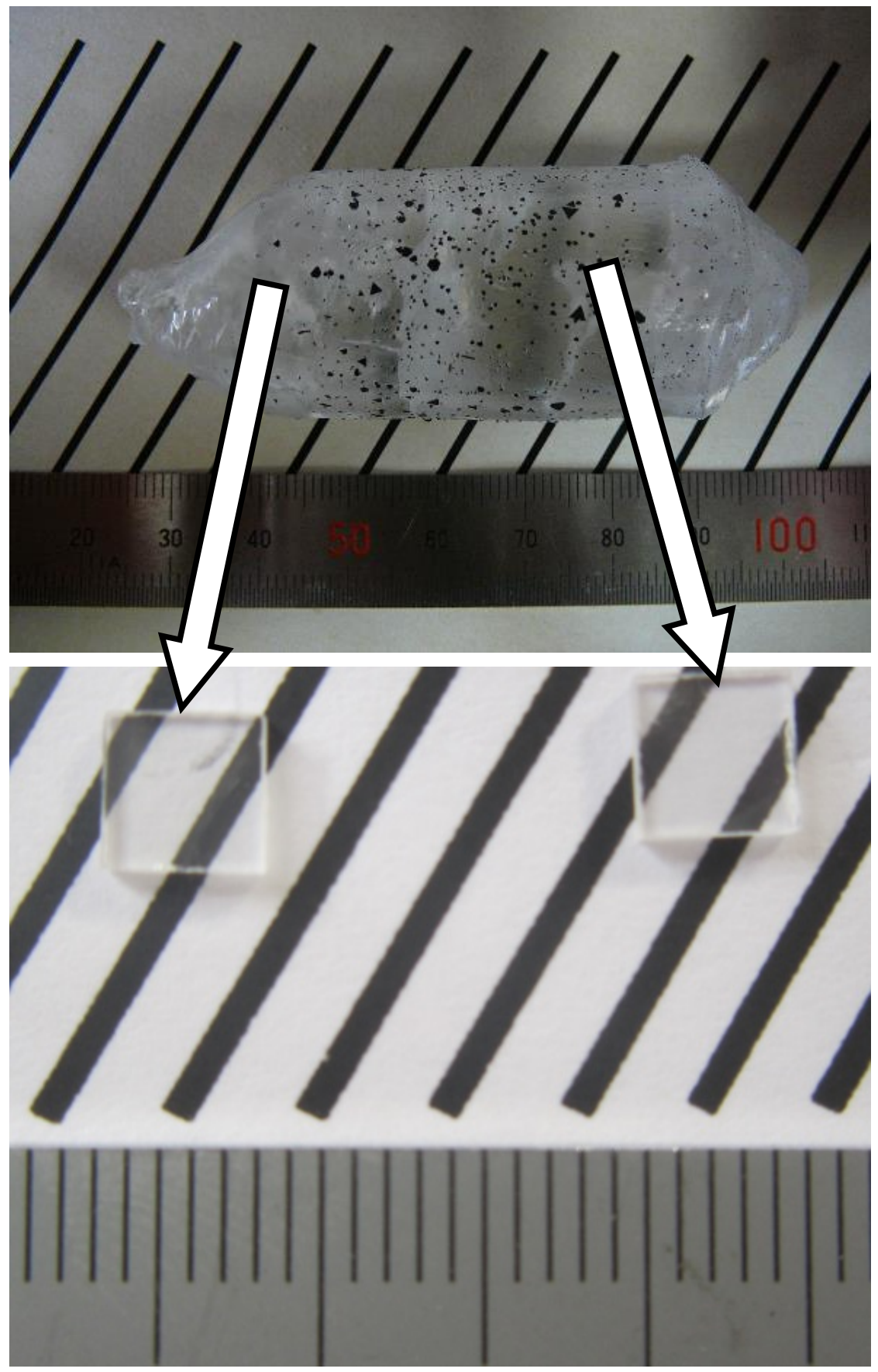

Fig.8. View of the Ce-doped La-GPS crystal grown from the $\mathrm{La}_{0.98} \mathrm{Ce}_{0.02} \mathrm{Gd}_{2.0} \mathrm{Si}_{2} \mathrm{O}_{7}$ melt by Czochralski method (top) and appearance of the Sample A (bottom, left) and Sample B (bottom right) cut from the crystal at different solidification fractions. Scales are in $\mathrm{mm}$ 

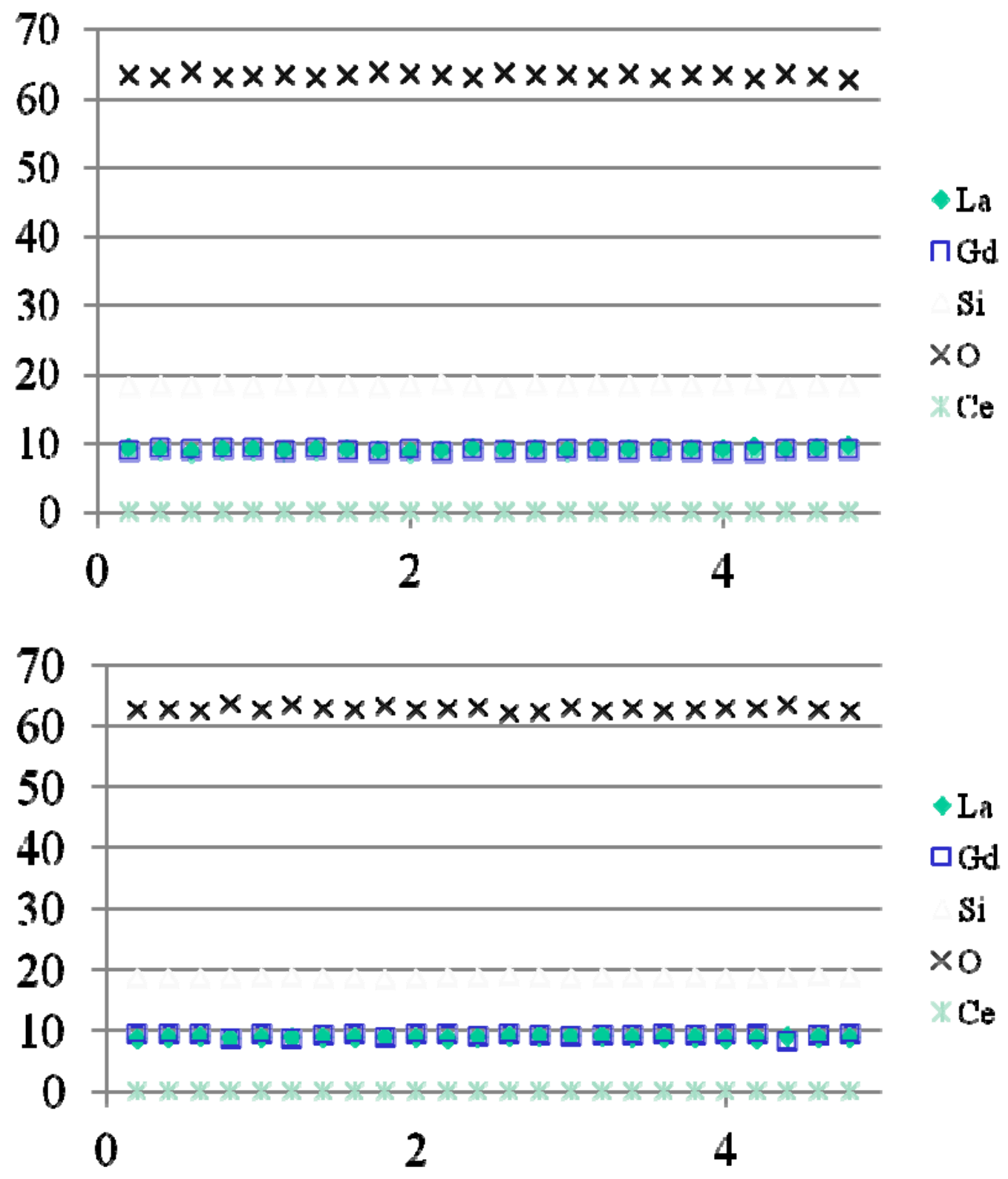

Fig.9. Distribution of Ce-doped La-GPS components along the growth axis. 

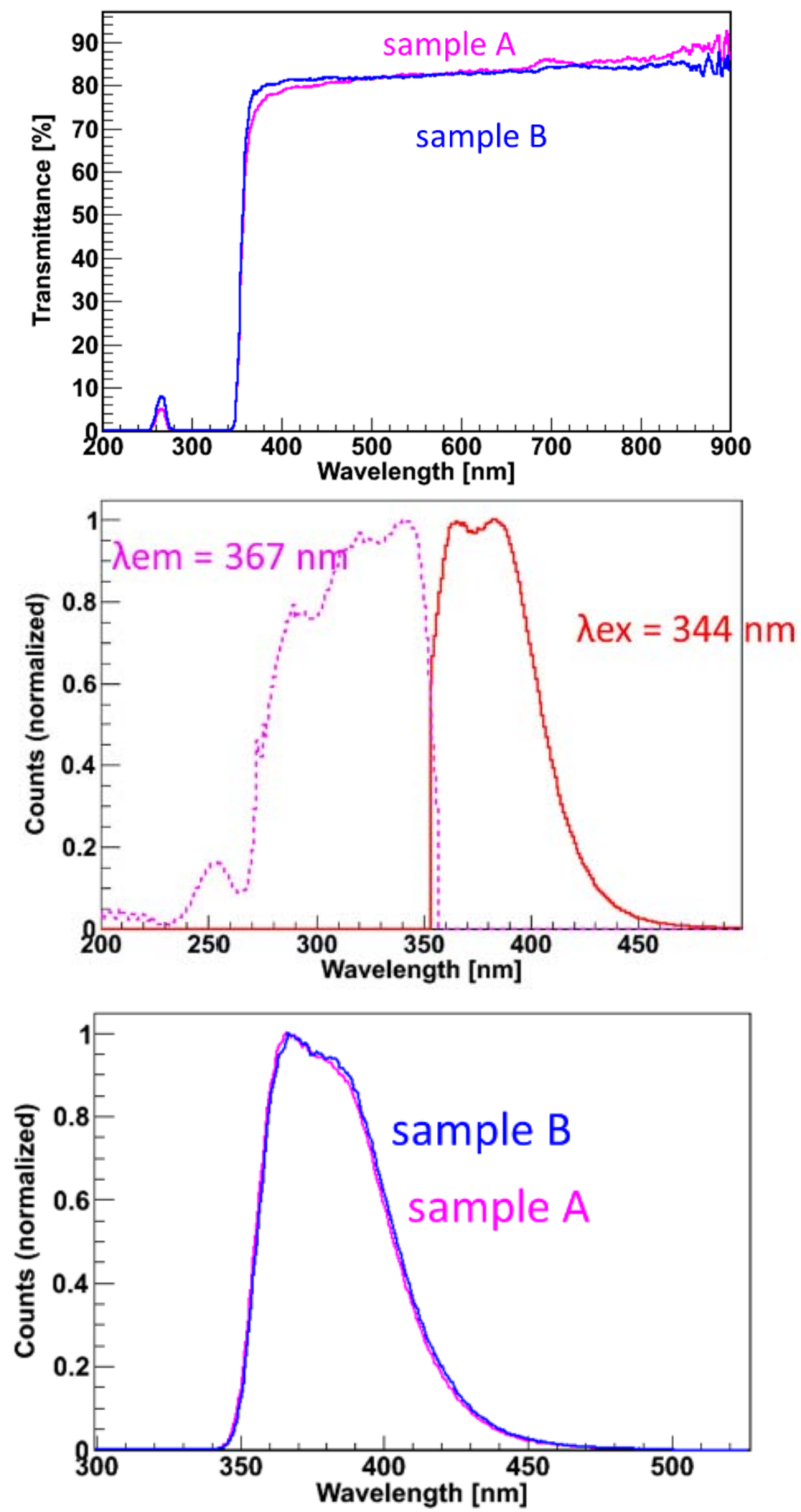

Fig.10 Transmittance (top), photo-luminescence (middle), and radio-luminescence (bottom) spectra of the samples A and B illustrated in Fig.8. 


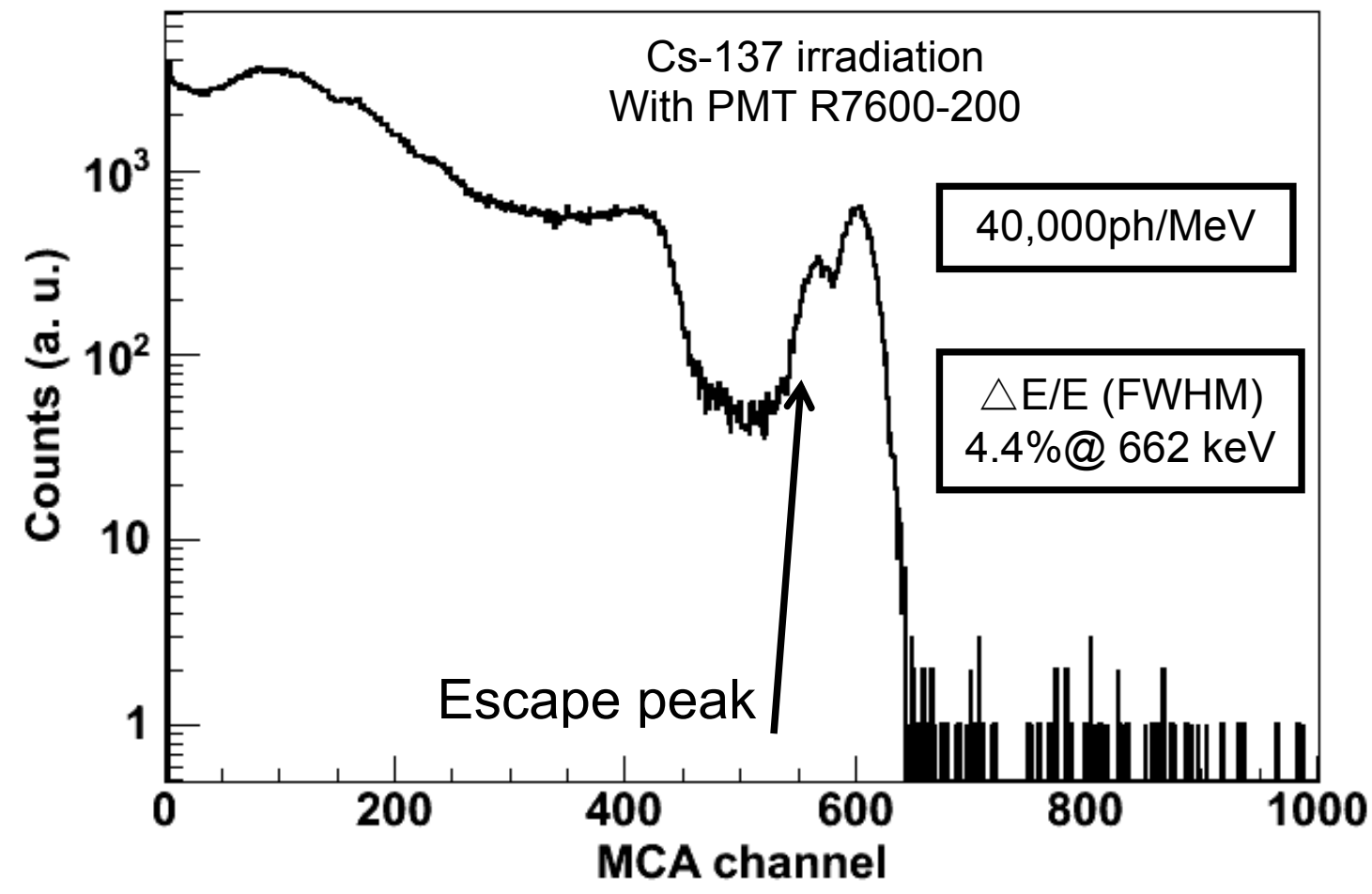

Fig.11. Pulse height spectra of Ce-doped La-GPS crystals recorded under ${ }^{137} \mathrm{Cs}$ irradiation. 